\title{
Fabrication of quantum dot/silica core-shell particles immobilizing Au nanoparticles and their dual imaging functions
}

\author{
Yoshio Kobayashi ${ }^{1} \cdot$ Hiromu Matsudo ${ }^{1}$ Ting-ting $\mathrm{Li}^{1} \cdot \mathrm{Kyosuke} \mathrm{Shibuya}^{1} \cdot$ \\ Yohsuke Kubota $^{2} \cdot$ Takahiro Oikawa $^{2} \cdot$ Tomohiko Nakagawa $^{2} \cdot$ Kohsuke Gonda $^{2}$
}

Received: 4 December 2014 / Accepted: 17 March 2015/Published online: 31 March 2015

(c) The Author(s) 2015. This article is published with open access at Springerlink.com

\begin{abstract}
The present work proposes preparation methods for quantum dot/silica $\left(\mathrm{QD} / \mathrm{SiO}_{2}\right)$ core-shell particles that immobilize Au nanoparticles $\left(\mathrm{QD} / \mathrm{SiO}_{2} / \mathrm{Au}\right)$. A colloid solution of $\mathrm{QD} / \mathrm{SiO}_{2}$ core-shell particles with an average size of $47.0 \pm 6.1 \mathrm{~nm}$ was prepared by a sol-gel reaction of tetraethyl orthosilicate in the presence of the QDs with an average size of $10.3 \pm 2.1 \mathrm{~nm}$. A colloid solution of $\mathrm{Au}$ nanoparticles with an average size of $17.9 \pm 1.3 \mathrm{~nm}$ was prepared by reducing $\mathrm{Au}^{3+}$ ions with sodium citrate in water at $80{ }^{\circ} \mathrm{C}$. Introduction of amino groups to $\mathrm{QD} / \mathrm{SiO}_{2}$ particle surfaces was performed using (3-aminopropyl)triethoxysilane $\left(\mathrm{QD} / \mathrm{SiO}_{2}-\mathrm{NH}_{2}\right)$. The $\mathrm{QD} / \mathrm{SiO}_{2} / \mathrm{Au}$ particles were fabricated by mixing the Au particle colloid solution and the $\mathrm{QD} / \mathrm{SiO}_{2}-\mathrm{NH}_{2}$ particle colloid solution. Values of radiant efficiency and computed tomography for the QD/ $\mathrm{SiO}_{2} / \mathrm{Au}$ particle colloid solution were $2.23 \times 10^{7}(\mathrm{p} / \mathrm{s} /$ $\left.\mathrm{cm}^{2} / \mathrm{sr}\right) /\left(\mu \mathrm{W} / \mathrm{cm}^{2}\right)$ at a QD concentration of $8 \times 10^{-7} \mathrm{M}$ and $1180 \pm 314$ Hounsfield units and an $\mathrm{Au}$ concentration of $5.4 \times 10^{-2} \mathrm{M}$. The $\mathrm{QD} / \mathrm{SiO}_{2} / \mathrm{Au}$ particle colloid solution was injected into a mouse chest wall. Fluorescence emitted from the colloid solution could be detected on the skin covering the chest wall. The colloid solution could also be X-ray-imaged in the chest wall. Consequently, the $\mathrm{QD} / \mathrm{SiO}_{2} / \mathrm{Au}$ particle colloid solution was found to have dual functions, i.e., fluorescence emission and X-ray
\end{abstract}

Yoshio Kobayashi

ykoba@mx.ibaraki.ac.jp

1 Department of Biomolecular Functional Engineering, College of Engineering, Ibaraki University,

4-12-1 Naka-narusawa-cho, Hitachi, Ibaraki 316-8511, Japan

2 Department of Medical Physics, Graduate School of Medicine, Tohoku University, Sendai, Miyagi 980-8575, Japan absorption in vivo, which makes the colloid solution suitable to function as a contrast agent for dual imaging processes.

Keywords Quantum dot $\cdot$ Au $\cdot$ Nanoparticle $\cdot$ Silica coating $\cdot$ Core-shell $\cdot$ Fluorescence imaging $\cdot \mathrm{X}$-ray imaging

\section{Introduction}

Nanoparticles of semiconductor compounds such as CdS, $\mathrm{CdSe}$, and CdTe exhibit unique fluorescent properties and are called quantum dots (QDs). QDs have often been used as a contrast agent for in vivo fluorescence imaging (Ozawa et al. 2013; Sapsford et al. 2013; Geißler et al. 2014).

Because these QDs contain cadmium, they might harm living tissues (Yang et al. 2012; Tassali et al. 2014; BerezaMalcolm et al. 2015). Coating the QDs with materials inert to living organisms forms core-shell particles with a QD core; the inert shell prevents contact with living tissues because of the physical barrier of the shell. Accordingly, forming such core-shell structures is a candidate method for reducing toxicity. Shell materials should be chemically inert in a wide variety of solvents and nontoxic to living organisms. Core-shell particles with QD nanoparticle cores must flow without aggregating in the blood vessels of an organism after injection because blood flow is weakened or stopped by such aggregation.

Silica is chemically inert and nontoxic relative to many solid materials (Hu et al. 2013; Young and Santra 2014; Zeng et al. 2014). Because silica particles form stable colloids in various dispersions (Mondragon et al. 2012; Bitter et al. 2013; Chou et al. 2014), silica-coated particles 
become highly dispersed, which provides steady particle flow in blood vessels. Accordingly, silica is a promising shell material. Silica particles can be easily fabricated via the Stöber method (Bell et al. 2012; Goertz et al. 2012; Neville et al. 2012; Börner et al. 2013). Several researchers have extended the Stöber method to produce QDs coated with silica, or $\mathrm{QD} / \mathrm{SiO}_{2}$ core-shell particles (Wang et al. 2012; Ma et al. 2014; Aubert et al. 2014). Their method uses a sol-gel reaction with silicone alkoxide and base catalyst in the presence of the QDs. Our research group has proposed an alternative method for producing $\mathrm{QD} / \mathrm{SiO}_{2}$ particles (Kobayashi et al. 2010a, b, 2012a, 2013a, 2015) and performed fluorescence imaging of mice tissues, into which the colloid nanoparticle solutions were injected (Kobayashi et al. 2013a, 2015).

Materials with high X-ray absorption properties can be applied for X-ray imaging techniques. In imaging, iodinated contrast agents are usually used to obtain clear images. Typical X-ray contrast agents that are commercially available are iodine compounds dissolved homogeneously in solvents at the molecular level. However, iodine compound X-ray contrast agents face a problem; they may provoke adverse events such as allergic reactions in patients (Lusic and Grinstaff 2013; Scoditti et al. 2013; Wendel et al. 2014), preventing their administration to such people. In addition to iodine compounds, $\mathrm{Au}$ is also promising for imaging because $\mathrm{Au}$ also highly absorbs $\mathrm{X}$-rays and is less toxic relative to the iodine compounds. From this viewpoint, Au nanoparticles have been examined with respect to their use as contrast agents for imaging tissues in living bodies at the nanometer level (Lusic and Grinstaff 2013; Cole et al. 2014; Betzer et al. 2014).

Materials composed of components that have different properties should have multiple functions. Considering the multi-functionalization of materials, particles containing QDs and Au will act as both a fluorescent contrast agent and an X-ray contrast agent. The present work proposes a method for fabricating composite particles composed of $\mathrm{QD} / \mathrm{SiO}_{2}$ core-shell particles and Au nanoparticles, or QD/ $\mathrm{SiO}_{2}$ core-shell particles on which $\mathrm{Au}$ nanoparticles are immobilized (QD/SiO $/ \mathrm{Au}$ ). QD/SiO 2 core-shell particles were fabricated according to the method outlined in our previous works (Kobayashi et al. 2010a, b, 2012a, 2013a, 2015), and amino groups were introduced onto their surface using silicone alkoxide with a terminal amino group. $\mathrm{Au}$ nanoparticles were prepared with a conventional method using citrate as a reducing reagent. The $\mathrm{QD} / \mathrm{SiO}_{2} /$ $\mathrm{Au}$ particles were fabricated by simply mixing the QD/ $\mathrm{SiO}_{2}$ core-shell particle colloid solution and the $\mathrm{Au}$ nanoparticle colloid solution. Imaging abilities based on both fluorescence and X-ray absorption of the composite particle colloid solution were also studied in the present work.

\section{Experimental}

\section{Chemicals}

Qdot $^{\circledR}$ (Invitrogen Co., catalog number: Q21371MP, concentration: $\left.8 \times 10^{-6} \mathrm{M}\right), \mathrm{CdSe}_{\mathrm{x}} \mathrm{Te}_{1-\mathrm{x}}$ nanoparticles coated with $\mathrm{ZnS}$ and then surface-modified with carboxyl groups, was the seed QD nanoparticle for the silica coating. Figure 1a shows a transmission electron microscope (TEM) image of these QDs. Their average size was $10.3 \pm 2.1 \mathrm{~nm}$. According to our previous work, the QD emits fluorescence with a peak at around $745 \mathrm{~nm}$ (Kobayashi et al. 2010b). For silica coating of the QD nanoparticles, the sol-gel silica source, catalyst, and solvent were tetraethyl orthosilicate (TEOS) (Kanto Chemical Co., Inc., $95 \%$ ), sodium hydroxide $(\mathrm{NaOH})$ (Kanto Chemical Co., Inc., $0.1 \mathrm{M}$ ), and ethanol (Kanto Chemical Co., Inc., $99.5 \%$ ), respectively. $\mathrm{Au}$ nanoparticles were prepared using hydrogen tetrachloroaurate (III) trihydrate $\left(\mathrm{HAuCl}_{4} \cdot 3 \mathrm{H}_{2} \mathrm{O}\right)$ (SigmaAldrich, $>98 \%)$ and trisodium citrate dihydrate (Na-cit) (Kanto Chemical, $99 \%$ ). (3-aminopropyl)triethoxysilane (APES) (Tokyo Chemical Industry, $98 \%$ ) was used for introducing amino groups on the $\mathrm{QD} / \mathrm{SiO}_{2}$ particle surface to increase the affinity between the Au particle surface and the $\mathrm{QD} / \mathrm{SiO}_{2}$ particle surface. All chemicals were used as received. Water that had been ion-exchanged and distilled with a Shimadzu SWAC-500 was used for all the preparations.
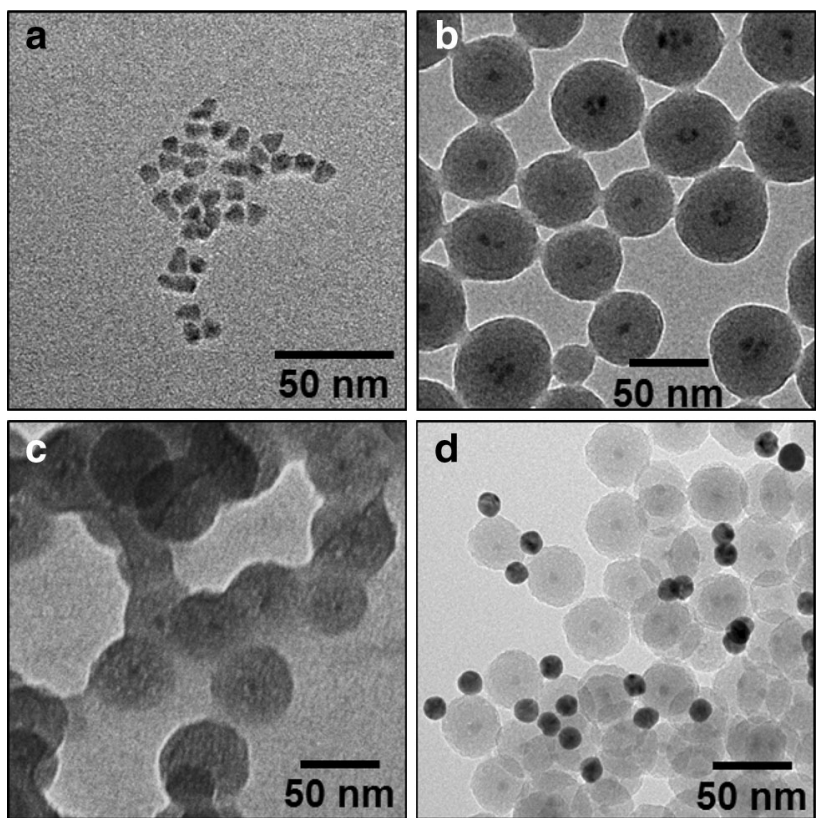

Fig. 1 TEM images of a QDs, b QD/SiO 2 particles, c $\mathrm{QD} / \mathrm{SiO}_{2}-\mathrm{NH}_{2}$ particles, and $\mathbf{d} \mathrm{QD} / \mathrm{SiO}_{2} / \mathrm{Au}$ particles 


\section{Preparation}

The QD nanoparticles were silica-coated via the sol-gel method using TEOS, similarly to the method outlined in our previous works (Kobayashi et al. 2010a, b, 2012a, $2013 \mathrm{a}, 2015)$. Solutions of $38.0 \mathrm{~mL}$ of $18.4 / 81.6(\mathrm{v} / \mathrm{v})$ water/ethanol and $11.8 \mathrm{~mL}$ of $4.24 \times 10^{-3} \mathrm{M}$ TEOS/ ethanol were added to $0.004 \mathrm{~mL}$ of the $8 \times 10^{-6} \mathrm{M} \mathrm{QD}$ colloid solution in turn. The sol-gel reaction was then initiated by rapidly injecting $0.2 \mathrm{~mL}$ of $0.1 \mathrm{M}$ aqueous $\mathrm{NaOH}$ into $49.8 \mathrm{~mL}$ of the QD/TEOS colloid solution, which resulted in the $(0.1 \mathrm{M}$ aqueous $\mathrm{NaOH}) /(\mathrm{QD} / \mathrm{TEOS}$ colloid solution) volume ratio of $0.402 \%$. The abovementioned amounts of solutions gave the initial concentrations of $6.4 \times 10^{-10} \mathrm{M} \mathrm{QD,} 1.0 \times 10^{-3} \mathrm{M}$ TEOS, $8 \mathrm{M}$ $\mathrm{H}_{2} \mathrm{O}$, and $4.0 \times 10^{-4} \mathrm{M} \mathrm{NaOH}$. The reaction proceeded for $24 \mathrm{~h}$ at room temperature. Our previous work indicated no serious effect of the silica coating on emission wavelength and fluorescence intensity of QDs (Kobayashi et al. 2010b). The QD/SiO ${ }_{2}$ colloid solution prepared in the present work was also considered to have the same fluorescence properties as the QD colloid solution. The $\mathrm{QD} / \mathrm{SiO}_{2}$ colloid solution was concentrated to a QD concentration of $3.2 \times 10^{-9} \mathrm{M}$ by evaporating the solvent, centrifuging, removing the supernatant, adding water, and redispersing the concentrated $\mathrm{QD} / \mathrm{SiO}_{2}$ colloid solution.

A freshly prepared $0.118 \mathrm{~mL}$ of $0.339 \mathrm{M} \mathrm{Na}$-cit aqueous solution was added to $24.9 \mathrm{~mL}$ of $2.41 \times 10^{-4} \mathrm{M} \mathrm{HAuCl}_{4}$ aqueous solution at a constant temperature of $80{ }^{\circ} \mathrm{C}$ under vigorous stirring, which resulted in initial concentrations of $2.4 \times 10^{-4} \mathrm{M} \mathrm{Au}$ and $1.6 \times 10^{-3} \mathrm{M} \mathrm{Na}$-cit.

For efficient immobilization of $\mathrm{Au}$ nanoparticles on the $\mathrm{QD} / \mathrm{SiO}_{2}$ particle surface, or production of $\mathrm{QD} / \mathrm{SiO}_{2} / \mathrm{Au}$ particles, amino groups were first introduced on the QD/ $\mathrm{SiO}_{2}$ particle surface using APES (QD/SiO $\left.-\mathrm{NH}_{2}\right)$, because the alkoxide groups of the APES were expected to react with the $\mathrm{OH}$ groups on the silica surface of the $\mathrm{QD} / \mathrm{SiO}_{2}$ particles. APES $(0.035 \mathrm{~mL})$ was added to $25 \mathrm{~mL}$ of the concentrated $\mathrm{QD} / \mathrm{SiO}_{2}$ colloid solution with the QD concentration of $3.2 \times 10^{-9} \mathrm{M}$ at room temperature, which resulted in an initial APES concentration of $6 \times 10^{-3} \mathrm{M}$. In a preliminary experiment, an iso-electric point of the $\mathrm{QD} / \mathrm{SiO}_{2}-\mathrm{NH}_{2}$ particles shifted to high $\mathrm{pH}$ with the introduction of amino groups, and the shift was the largest at the initial APES concentration of $6 \times 10^{-3} \mathrm{M}$ in an initial APES concentration range of $6 \times 10^{-5}$ to $6 \times 10^{-2} \mathrm{M}$, which indicated that efficient introduction of amino groups was performed at $6 \times 10^{-3} \mathrm{M}$. Thus, the initial APES concentration was adjusted to $6 \times 10^{-3} \mathrm{M}$ in the present work. The reaction time was $24 \mathrm{~h}$. The $\mathrm{QD} / \mathrm{SiO}_{2}-\mathrm{NH}_{2}$ colloid solution was concentrated to a $\mathrm{QD}$ concentration of
$1.28 \times 10^{-7} \mathrm{M}$ by centrifuging, removing the supernatant, adding ethanol, and redispersing the concentrated QD/ $\mathrm{SiO}_{2}-\mathrm{NH}_{2}$ colloid solution. For the Au nanoparticles' immobilization, ethanol, water, and the Au nanoparticle colloid solution were added in turn to the $\mathrm{QD} / \mathrm{SiO}_{2}-\mathrm{NH}_{2}$ particle colloid solution at $35{ }^{\circ} \mathrm{C}$, as the amino groups on the particle surface were expected to coordinate with the surface of $\mathrm{Au}$ nanoparticles. The initial concentrations of $\mathrm{QD}, \mathrm{Au}$, and $\mathrm{H}_{2} \mathrm{O}$ were $7.4 \times 10^{-10}, 5 \times 10^{-5}$, and $12.4 \mathrm{M}$, respectively. The $\mathrm{QD} / \mathrm{SiO}_{2} / \mathrm{Au}$ colloid solution was concentrated by evaporating the solvent, centrifuging, removing the supernatant, adding water, and redispersing the colloid solution, which produced a $\mathrm{QD} / \mathrm{SiO}_{2} / \mathrm{Au}$ colloid solution with a QD concentration of $8.0 \times 10^{-7} \mathrm{M}$ and an Au concentration of $5.4 \times 10^{-2} \mathrm{M}$

\section{Characterization}

The samples were characterized by ultra-visible (UV-VIS) spectroscopy, electrophoretic light scattering (ELS), and TEM. VIS extinction of the particle colloid solution was measured with a Shimadzu UV-3101PC (Kyoto, Japan) spectrophotometer. $\zeta$-potentials of the particles were measured by ELS to obtain information on the state of the particles. The ELS was performed with a Malvern Zetasizer Nano ZS90 (Worcestershire, UK). Either an $\mathrm{HCl}$ aqueous solution or an $\mathrm{NaOH}$ aqueous solution was added to the solution to vary the $\mathrm{pH}$ of the solution for the ELS measurement. The TEM imaging was performed using a JEOL JEM-2100 microscope operating at $200 \mathrm{kV}$. The TEM samples were prepared by dropping the nanoparticle suspensions onto a collodion-coated copper grid and evaporating them. Tens of particle diameters were measured using the TEM images to determine the volumeaveraged particle size and its standard deviation.

Fluorescence imaging and X-ray imaging with the particle colloid solutions were performed using a Xenogen IVIS 100 fluorometer in vivo imaging system (IVIS) and an Aloka La theta LCT-200 CT system, Japan), respectively, which were also used in our previous works (Ayame et al. 2011; Kobayashi et al. 2011, 2012b, 2013a, b, c, d, 2014, 2015). CT values were estimated on the basis of CT values of -1000 and 0 for air and water, respectively. For mouse imaging, the colloid solution $(50 \mu \mathrm{L})$ was injected into the chest wall of an anesthetized mouse. Fluorescence emitted from inside the colloid-injected mouse was detected with the IVIS. X-ray images of the colloid-injected mouse were taken by transmitting X-rays through the mouse with the CT system. The mice used were ICR mice, aged 5-6 weeks. 


\section{Results and discussion}

\section{Particle morphology}

Figure $1 \mathrm{~b}$ shows a TEM micrograph of the $\mathrm{QD} / \mathrm{SiO}_{2}$ nanoparticles. The darker and lighter sections of the particles were determined to be the QD particles and silica, respectively, because of their differing electron densities. Most of the particles contained a few QD cores, and the average particle size was $47.0 \pm 6.1 \mathrm{~nm}$. Figure 2a shows the $\zeta$-potential of the $\mathrm{QD} / \mathrm{SiO}_{2}$ particles as a function of $\mathrm{pH}$. The $\zeta$-potential decreased and passed through an isoelectric point (IEP) of 3.1 as the $\mathrm{pH}$ increased. According to studies performed by several researchers (Kim et al. 2009; Jiang et al. 2012; Zhang et al. 2013), silica particles produced by a sol-gel method using silicon alkoxide have an IEP of 2.0-4.0. The IEP of $\mathrm{QD} / \mathrm{SiO}_{2}$ particles was similar to the IEP for silica particles. This implied that the QD surface was covered with silica, which was supported by the TEM observations (Fig. 1b).

$\mathrm{The} \mathrm{QD} / \mathrm{SiO}_{2}-\mathrm{NH}_{2}$ nanoparticles dispersed well in water, or they were colloidally stable, which indicated no serious effect of the APES addition on their colloidal stability in water. Figure 1c shows a TEM micrograph of the $\mathrm{QD} / \mathrm{SiO}_{2}-\mathrm{NH}_{2}$ nanoparticles. Some particles appeared to form aggregates composed of several particles that were likely to precipitate. However, no precipitates were found in the particle colloid solution. Accordingly, the aggregates were thought to be produced during the preparation of TEM samples accompanied by the evaporation of solvent on the TEM grid. Similarly to the $\mathrm{QD} / \mathrm{SiO}_{2}$ nanoparticles, particles containing a few QD cores were observed. Their average particle size was $42.4 \pm 4.3 \mathrm{~nm}$, which was considered to be almost the same as that of the $\mathrm{QD} / \mathrm{SiO}_{2}$ nanoparticles within the statistical error. This similarity indicated that their core-shell structure was chemically stable, even after the amination process. Figure $2 \mathrm{~b}$ shows

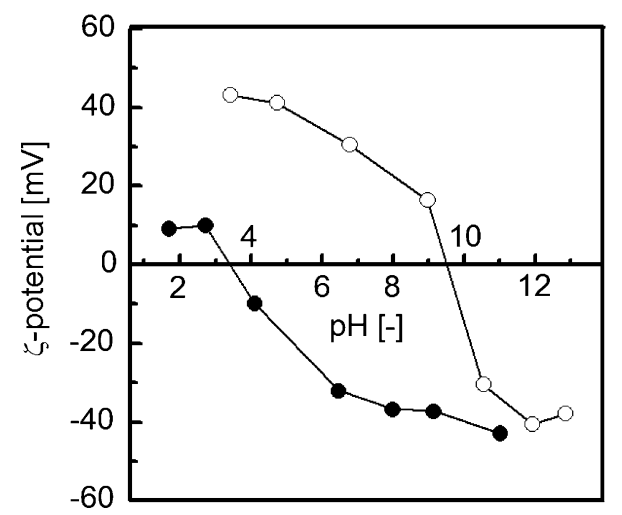

Fig. 2 ל-potentials of (filled circle) $\mathrm{QD} / \mathrm{SiO}_{2}$ particles and (unfilled circle) $\mathrm{QD} / \mathrm{SiO}_{2}-\mathrm{NH}_{2}$ particles as a function of $\mathrm{pH}$ the $\zeta$-potential of the $\mathrm{QD} / \mathrm{SiO}_{2}-\mathrm{NH}_{2}$ particles as a function of $\mathrm{pH}$. Similarly to the case of $\mathrm{QD} / \mathrm{SiO}_{2}$ nanoparticles, the $\zeta$-potential decreased and passed through an IEP with an increase in $\mathrm{pH}$. The IEP was 9.5, which was higher than that of the $\mathrm{QD} / \mathrm{SiO}_{2}$ nanoparticles. This higher IEP was within a range of 9-11, which is typical of acid dissociation constants for amino groups in many types of amines, such as ammonia, alkylamine, and dialkylamine. Accordingly, this result confirmed that the amino groups were successfully introduced onto the particle surface.

One of the insets in Fig. 3 shows a photograph of the Au nanoparticle colloid solution. After the addition of the Nacit solution to the $\mathrm{HAuCl}_{4}$ solution, the color of the solution turned wine-red within a few minutes, which implied the formation of $\mathrm{Au}$ nanoparticles. Figure 3 shows the extinction spectrum of the Au nanoparticle colloid solution. A peak observed at $521 \mathrm{~nm}$ could be attributed to the surface plasmon resonance of Au nanoparticles (Lismont and Dreesen 2012; Liang et al. 2012; Ujihara and Imae 2013). This measurement confirmed that Au nanoparticles were produced, which supports the implication of $\mathrm{Au}$ nanoparticle formation. A TEM image of the Au nanoparticles is shown in another inset in Fig. 3. Spherical Au nanoparticles with an average size of $17.9 \pm 1.3 \mathrm{~nm}$ were observed.

Figure 1d shows a TEM micrograph of the $\mathrm{QD} / \mathrm{SiO}_{2} / \mathrm{Au}$ nanoparticles. All the Au nanoparticles were immobilized on the particle surface, indicating that the Au nanoparticles' immobilization was successfully performed with the present method. Several $\mathrm{Au}$ nanoparticles-free particles were also observed, since a number-ratio of Au nanoparticles/QD/SiO ${ }_{2}-\mathrm{NH}_{2}$ nanoparticles was small compared to 1/1. Accordingly, optimization of fabrication conditions such as concentrations of $\mathrm{Au}$ nanoparticles and $\mathrm{QD} / \mathrm{SiO}_{2}-$ $\mathrm{NH}_{2}$ nanoparticles in the final colloid solution, reaction

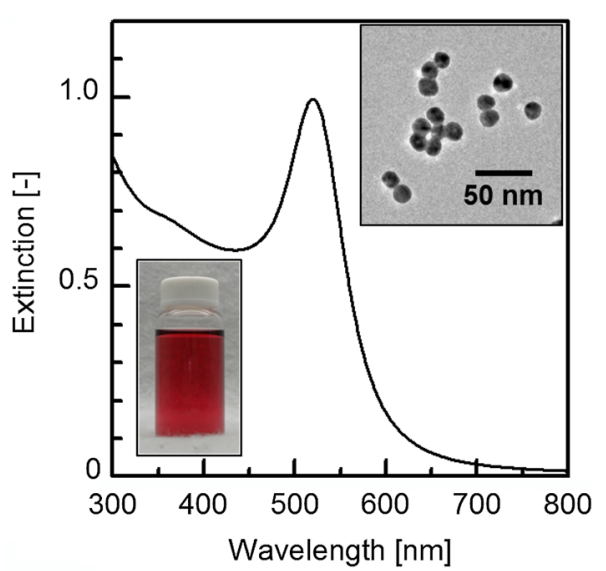

Fig. 3 Extinction spectrum of a colloid solution of Au nanoparticles. Insets show a photograph of the colloid solution and a TEM image of the particles 


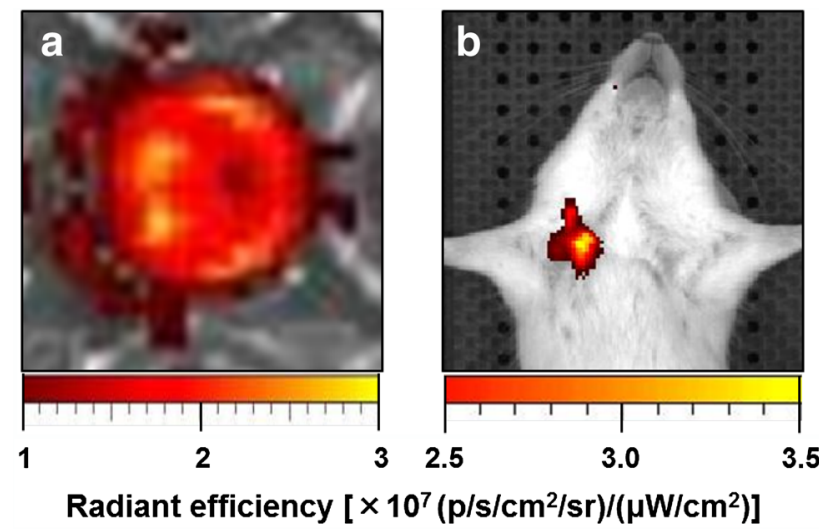

Fig. 4 IVIS images of a the $\mathrm{QD} / \mathrm{SiO}_{2} / \mathrm{Au}$ particle colloid solution and $\mathbf{b}$ a mouse after the colloid solution was injected into its chest wall

temperature and stirring rate is required to improve the efficiency of Au nanoparticles' immobilization. This improvement may also improve dual imaging ability of the $\mathrm{QD} / \mathrm{SiO}_{2} / \mathrm{Au}$ particle colloid solution.

\section{Imaging of the $\mathrm{QD} / \mathrm{SiO}_{2} / \mathrm{Au}$ particle colloid solution}

Figure 4a shows an IVIS image of the $\mathrm{QD} / \mathrm{SiO}_{2} / \mathrm{Au}$ particle colloid solution. The colloid solution was successfully imaged. Its radiant efficiency (RE) was $2.23 \times 10^{7}(\mathrm{p} / \mathrm{s} /$ $\left.\mathrm{cm}^{2} / \mathrm{sr}\right) /\left(\mu \mathrm{W} / \mathrm{cm}^{2}\right)$. The value was converted into a value with respect to QD concentration to compare it with that of a commercial QD. Because the colloid solution had a QD concentration of $8 \times 10^{-7} \mathrm{M}$, the converted $\mathrm{RE}$ was $2.79 \times 10^{13}\left(\mathrm{p} / \mathrm{s} / \mathrm{cm}^{2} / \mathrm{sr}\right) /\left(\mu \mathrm{W} / \mathrm{cm}^{2}\right) / \mathrm{M}$. According to our previous work (Kobayashi et al. 2013a), the RE of QDs was $2.93 \times 10^{9}\left(\mathrm{p} / \mathrm{s} / \mathrm{cm}^{2} / \mathrm{sr}\right) /\left(\mu \mathrm{W} / \mathrm{cm}^{2}\right)$ at a QD concentration of $1 \times 10^{-7} \mathrm{M}$, which corresponded to a converted $\mathrm{RE}$ of $2.93 \times 10^{16}\left(\mathrm{p} / \mathrm{s} / \mathrm{cm}^{2} / \mathrm{sr}\right) /\left(\mu \mathrm{W} / \mathrm{cm}^{2}\right) / \mathrm{M}$. The converted $\mathrm{RE}$ for the $\mathrm{QD} / \mathrm{SiO}_{2} / \mathrm{Au}$ particle colloid solution was smaller than that for a commercial QD. The Au nanoparticle colloid solution absorbed visible light in a wide range around the wavelength of $521 \mathrm{~nm}$, as shown in Fig. 3. The fluorescence from the $\mathrm{QD} / \mathrm{SiO}_{2} / \mathrm{Au}$ particles was probably diminished by this absorption, though the mechanism is still unclear. Although the converted RE for the QD/SiO$/$ Au particle colloid solution was small, the intensity of the RE was high enough to image a mouse, based on our previous experience in animal experiments.

Figure $5 \mathrm{~b}$ shows an $\mathrm{X}$-ray image of the $\mathrm{QD} / \mathrm{SiO}_{2} / \mathrm{Au}$ particle colloid solution. For comparison, an X-ray image of water is shown in Fig. 5a. The white contrast in the image of the $\mathrm{QD} / \mathrm{SiO}_{2} / \mathrm{Au}$ particle colloid solution was lighter than that for water. The computed tomography (CT) value of the $\mathrm{QD} / \mathrm{SiO}_{2} / \mathrm{Au}$ particle colloid solution was $1180 \pm 314$ Hounsfield units (HU) at an Au concentration of $5.4 \times 10^{-2} \mathrm{M}$. This value was converted into a value with respect to the molar concentration of subject materials such as $\mathrm{Au}$ and I (converted CT value) to compare it with that of a commercial contrast agent. The converted CT value with respect to the Au concentration was estimated to be $2.19 \times 10^{4} \mathrm{HU} / \mathrm{M}$. According to our previous work (Kobayashi et al. 2013c), the converted CT value with respect to the iodine concentration for Iopamiron 300 is $4.76 \times 10^{3} \mathrm{HU} / \mathrm{M}$. The converted CT value of the QD/ $\mathrm{SiO}_{2} / \mathrm{Au}$ particle colloid solution was larger than that of Iopamiron 300. Because gold absorbs X-rays more than iodine on the atomic level because of its large atomic number, a larger converted CT value was shown for the $\mathrm{QD} / \mathrm{SiO}_{2} / \mathrm{Au}$ particle colloid solution. Thus, it was confirmed that the $\mathrm{QD} / \mathrm{SiO}_{2} / \mathrm{Au}$ particle colloid solution had an ability to function as a highly sensitive X-ray contrast agent.

\section{Mouse imaging}

Figure 5c shows an IVIS image of a mouse after the injection of the $\mathrm{QD} / \mathrm{SiO}_{2} / \mathrm{Au}$ particle colloid solution. Fluorescence was clearly observed on the chest of the mouse after injection into its chest wall, which meant that fluorescence penetrated through the chest skin from inside the mouse to outside. Its radiant efficiency was $3.30 \times 10^{7}$ $\left(\mathrm{p} / \mathrm{s} / \mathrm{cm}^{2} / \mathrm{sr}\right) /\left(\mu \mathrm{W} / \mathrm{cm}^{2}\right)$. This value was ca. 1.5 times larger than the value of $2.23 \times 10^{7}\left(\mathrm{p} / \mathrm{s} / \mathrm{cm}^{2} / \mathrm{sr}\right) /\left(\mu \mathrm{W} / \mathrm{cm}^{2}\right)$ for the $\mathrm{QD} / \mathrm{SiO}_{2} / \mathrm{Au}$ particle colloid solution, which indicated that the $\mathrm{QD} / \mathrm{SiO}_{2} / \mathrm{Au}$ particle colloid solution could emit strong fluorescence even inside living bodies without quenching.
Fig. 5 CT images of a water, b the $\mathrm{QD} / \mathrm{SiO}_{2} / \mathrm{Au}$ particle colloid solution, and $\mathbf{c}$ a mouse after the colloid solution was injected into its chest wall. The $\mathrm{QD} / \mathrm{SiO}_{2} / \mathrm{Au}$ particle colloid solution was observed in the chest wall, as shown by the red circle
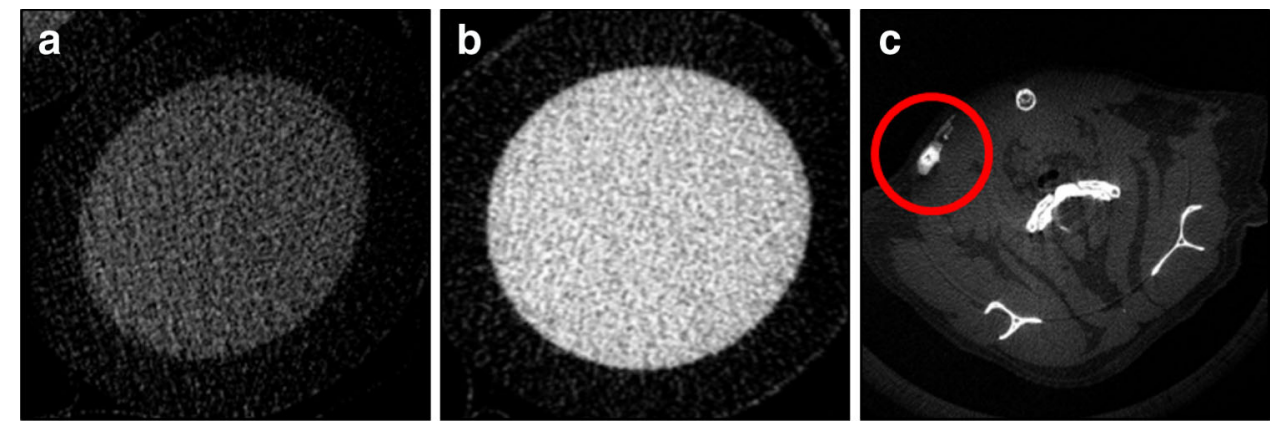

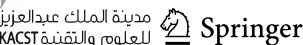


The detection of large radiant efficiency implied that the $\mathrm{QD} / \mathrm{SiO}_{2} / \mathrm{Au}$ particles were accumulated in the chest wall, though the reason for the large radiant efficiency is still unclear.

Figure 5c shows an X-ray image of the mouse after it was injected with the $\mathrm{QD} / \mathrm{SiO}_{2} / \mathrm{Au}$ particle colloid solution. The location of the particle colloid solution could be recognized clearly at its chest wall because of its light contrast. Its CT value was $1060 \pm 374 \mathrm{HU}$, which was as high as the value of $1180 \pm 314 \mathrm{HU}$ for the $\mathrm{QD} / \mathrm{SiO}_{2} / \mathrm{Au}$ particle colloid solution. Similarly to the fluorescence imaging, it was found that the $\mathrm{QD} / \mathrm{SiO}_{2} / \mathrm{Au}$ particle colloid solution could be clearly observed even inside living bodies without quenching.

Another result of note is that when the mouse that was injected with the $\mathrm{QD} / \mathrm{SiO}_{2} / \mathrm{Au}$ particle colloid solution was imaged simultaneously with the IVIS and X-ray, the position imaged by the IVIS was the same as that from X-ray imaging. This result suggests that the colloid solution can function as a contrast agent for dual imaging processes.

\section{Conclusion}

$\mathrm{QD} / \mathrm{SiO}_{2}$ particles averaging $47.0 \pm 6.1 \mathrm{~nm}$ in size were produced via the sol-gel method using TEOS and $\mathrm{NaOH}$ in a water/ethanol solution containing $\mathrm{QDs}$. The $\mathrm{QD} / \mathrm{SiO}_{2}$ particles were aminated by reacting silanol groups on the $\mathrm{QD} / \mathrm{SiO}_{2}$ particle surface and alkoxide groups in APES. Au nanoparticles averaging $17.9 \pm 1.3 \mathrm{~nm}$ in size were produced by reducing $\mathrm{HAuCl}_{4}$ with $\mathrm{Na}$-cit in water. The $\mathrm{Au}$ nanoparticles were immobilized on particles via the reaction of amino groups on the $\mathrm{QD} / \mathrm{SiO}_{2}$ particle surface and the Au particle surface. A $\mathrm{QD} / \mathrm{SiO}_{2} / \mathrm{Au}$ particle colloid solution with a QD concentration of $8 \times 10^{-7} \mathrm{M}$ and an Au concentration of $5.4 \times 10^{-2} \mathrm{M}$ had a radiant efficiency of $2.23 \times 10^{7}\left(\mathrm{p} / \mathrm{s} / \mathrm{cm}^{2} / \mathrm{sr}\right) /\left(\mu \mathrm{W} / \mathrm{cm}^{2}\right)$ and a CT value of $1180 \pm 314 \mathrm{HU}$. After injection of the $\mathrm{QD} / \mathrm{SiO}_{2} / \mathrm{Au}$ particle colloid solution into the chest wall of a mouse, the colloid solution could be detected simultaneously with IVIS and CT on the skin covering the chest wall and in the chest wall, respectively. Accordingly, the $\mathrm{QD} / \mathrm{SiO}_{2} / \mathrm{Au}$ particle colloid solution has the potential to be used as a contrast agent with dual functions for techniques such as fluorescence emission and $\mathrm{X}$-ray absorption in vivo.

Acknowledgments This work was supported by JSPS KAKENHI Grant Number 24310085, and by a Grant-in-Aid for Scientific Research on Innovative Areas "Nanomedicine Molecular Science" (No. 2306) from the Ministry of Education, Culture, Sports, Science, and Technology of Japan. We express our thanks to Prof. T. Noguchi at the College of Science of Ibaraki University, Japan (current affiliation: Faculty of Arts and Science of Kyusyu University, Japan) for his help with the TEM observations.
Open Access This article is distributed under the terms of the Creative Commons Attribution License which permits any use, distribution, and reproduction in any medium, provided the original author(s) and the source are credited.

\section{References}

Aubert T, Soenen SJ, Wassmuth D, Cirillo M, Deun RV, Braeckmans $\mathrm{K}$, Hens Z (2014) Bright and stable CdSe/CdS@ $\mathrm{SiO}_{2}$ nanoparticles suitable for long-term cell labeling. ACS Appl Mater Interfaces 6:11714-11723

Ayame T, Kobayashi Y, Nakagawa T, Gonda K, Takeda M, Ohuchi N (2011) Preparation of silica-coated AgI nanoparticles by an amine-free process and their X-ray imaging properties. J Ceram Soc Jpn 119:397-401

Bell NC, Minelli C, Tompkins J, Stevens MM, Shard AG (2012) Emerging techniques for submicrometer particle sizing applied to Stöber silica. Langmuir 28:10860-10872

Bereza-Malcolm LT, Mann G, Franks AE (2015) Environmental sensing of heavy metals through whole cell microbial biosensors: a synthetic biology approach. ACS Synth Biol. doi:10.1021/ sb500286r

Betzer O, Shwartz A, Motiei M, Kazimirsky G, Gispan I, Damti E, Brodie C, Yadid G, Popovtzer R (2014) Nanoparticle-based CT imaging technique for longitudinal and quantitative stem cell tracking within the brain: application in neuropsychiatric sisorders. ACS Nano 8:9274-9285

Bitter JL, Duncan GA, Beltran-Villegas DJ, Fairbrother DH, Bevan Michael A (2013) Anomalous silica colloid stability and gel layer mediated interactions. Langmuir 29:8835-8844

Börner M, Noisser T, Reichenauer G (2013) Cross-linked monolithic xerogels based on silica nanoparticles. Chem Mater 25:3648-3653

Chou KS, Liu HL, Kao LH, Yang CM, Huang SH (2014) A quick and simple method to test silica colloids' ability toresist aggregation. Colloids Surf A 448:115-118

Cole LE, Vargo-Gogola T, Roeder RK (2014) Contrast-enhanced $\mathrm{X}$-ray detection of breast microcalcifications in a murine model using targeted gold nanoparticles. ACS Nano 8:7486-7496

Geißler D, Linden S, Liermann K, Wegner KD, Charbonnière LJ, Hildebrandt N (2014) Lanthanides and quantum dots as Förster resonance energy transfer agents for diagnostics and cellular imaging. Inorg Chem 53:1824-1838

Goertz V, Gutsche A, Dingenouts N, Nirschl H (2012) Small-angle X-ray scattering study of the formation of colloidal SiO2 Stöber multiplets. J Phys Chem C 116:26938-26946

Hu Y, Shi Y, Jiang H, Huang G, Li C (2013) Scalable preparation of ultrathin silica-coated Ag nanoparticles for SERS application. ACS Appl Mater Interfaces 5:10643-10649

Jiang S, Zhuang J, Wang C, Li J, Yang W (2012) Highly efficient adsorption of DNA on $\mathrm{Fe}^{3+}$-iminodiacetic acid modified silica particles. Colloids Surf A 409:143-148

Kim JM, Chang SM, Kim S, Kim KS, Kim J, Kim WS (2009) Design of $\mathrm{SiO}_{2} / \mathrm{ZrO}_{2}$ core-shell particles using the sol-gel process. Ceram Inter 35:1243-1247

Kobayashi Y, Nozawa T, Takeda M, Ohuchi N, Kasuya A (2010a) Direct silica-coating of quantum dots. J Chem Eng Jpn 43:490-493

Kobayashi Y, Nozawa T, Nakagawa T, Gonda K, Takeda M, Ohuchi N, Kasuya A (2010b) Direct coating of quantum dots with silica shell. J Sol-Gel Sci Technol 55:79-85

Kobayashi Y, Inose H, Nakagawa T, Gonda K, Takeda M, Ohuchi N, Kasuya A (2011) Control of shell thickness in silica-coating of 
Au nanoparticles and their X-ray imaging properties. J Colloid Interface Sci 358:329-333

Kobayashi Y, Nozawa T, Nakagawa T, Gonda K, Takeda M, Ohuchi N (2012a) Fabrication and fluorescence properties of multilayered core-shell particles composed of quantum dot, gadolinium compound and silica. J Mater Sci 47:1852-1859

Kobayashi Y, Ayame T, Nakagawa T, Gonda K, Ohuchi N (2012b) $\mathrm{X}$-ray imaging technique using colloid solution of AgI/silica/ poly(ethylene glycol) nanoparticles. Mater Focus 1:127-130

Kobayashi Y, Matsudo H, Nakagawa T, Kubota Y, Gonda K, Takeda M, Ohuchi N (2013a) In-vivo fluorescence imaging technique using colloid solution of multiple quantum dots/silica/poly(ethylene glycol) nanoparticles. J Sol-Gel Sci Technol 66:31-37

Kobayashi Y, Inose H, Nakagawa T, Kubota Y, Gonda K, Ohuchi N (2013b) X-ray imaging technique using colloid solution of Au/ silica core-shell nanoparticles. J. Nanostruct Chem 3:62

Kobayashi Y, Inose H, Nagasu R, Nakagawa T, Kubota Y, Gonda K, Ohuchi N (2013c) X-ray imaging technique using colloid solution of $\mathrm{Au} / \mathrm{silica} / \mathrm{poly}($ ethylene glycol) nanoparticles. Mater Res Innov 17:507-514

Kobayashi Y, Ayame T, Nakagawa T, Kubota Y, Gonda K, Ohuchi N (2013d) Preparation of AgI/silica/poly(ethylene glycol) nanoparticle colloid solution and $\mathrm{X}$-ray imaging using it. ISRN Nanomater 2013:670402

Kobayashi Y, Nagasu R, Shibuya K, Nakagawa T, Kubota Y, Gonda K, Ohuchi N (2014) Synthesis of a colloid solution of silicacoated gold nanoparticles for X-ray imaging applications. J Nanopart Res 16:2551

Kobayashi Y, Matsudo H, Kubota Y, Nakagawa T, Gonda K, Ohuchi N (2015) Preparation of silica-coated quantum dot nanoparticle colloid solutions and their application in in vivo fluorescence imaging. J Chem Eng Jpn 48:112-117

Liang A, Liu Q, Wen G, Jiang Z (2012) The surface-plasmonresonance effect of nanogold/silver and its analytical applications. Trends Anal Chem 37:32-47

Lismont M, Dreesen L (2012) Comparative study of Ag and Au nanoparticles biosensors based on surface plasmon resonance phenomenon. Mater Sci Eng C 32:1437-1442

Lusic H, Grinstaff MW (2013) X-ray-computed tomography contrast agents. Chem Rev 113:1641-1666

Ma Y, Li Y, Zhong X (2014) Silica coating of luminescent quantum dots prepared in aqueous media for cellular labeling. Mater Res Bull 60:543-551

Mondragon R, Julia JE, Barba A, Jarque JC (2012) Characterization of silica-water nanofluids dispersed with an ultrasound probe: a study of their physical properties and stability. Powder Technol 224:138-146

Neville F, Zin AM, Jameson GJ, Wanless EJ (2012) Preparation and characterization of colloidal silica particles under mild conditions. J Chem Educ 89:940-942

Ozawa T, Yoshimura H, Kim SB (2013) Advances in fluorescence and bioluminescence imaging. Anal Chem 85:590-609

Sapsford KE, Algar WR, Berti L, Gemmill KB, Casey BJ, Oh E, Stewart MH, Medintz IL (2013) Functionalizing nanoparticles with biological molecules: developing chemistries that facilitate nanotechnology. Chem Rev 113:1904-2074

Scoditti E, Massaro M, Montinari MR (2013) Endothelial safety of radiological contrast media: why being concerned. Vasc Pharmacol 58:48-53

Tassali N, Kotera N, Boutin C, Léonce E, Boulard Y, Rousseau B, Dubost E, Taran F, Brotin T, Dutasta JP, Berthault P (2014) Smart detection of toxic metal ions, $\mathrm{Pb}^{2+}$ and $\mathrm{Cd}^{2+}$, using a ${ }^{129}$ Xe NMR-based densor. Anal Chem 86:1783-1788

Ujihara M, Imae T (2013) Versatile one-pot synthesis of confeito-like $\mathrm{Au}$ nanoparticles and their surface-enhanced Raman scattering effect. Colloids Surf A 436:380-385

Wang S, Li C, Yang P, Ando M, Murase N (2012) Silica encapsulation of highly luminescent hydrophobic quantum dots by two-step microemulsion method. Colloids Surf A 395:24-31

Wendel FM, Eversloh CL, Machek EJ, Duirk SE, Plewa MJ, Richardson SD, Ternes TA (2014) Transformation of Iopamidol during chlorination. Environ Sci Technol 48:12689-12697

Yang Y, Mathieu JM, Chattopadhyay S, Miller JT, Wu T, Shibata T, Guo W, Alvarez PJJ (2012) Defense mechanisms of pseudomonas aeruginosa PAO1 against quantum dots and their released heavy metals. ACS Nano 6:6091-6098

Young M, Santra S (2014) Copper (Cu)-ailica nanocomposite containing valence-engineered $\mathrm{Cu}$ : a new strategy for improving the antimicrobial efficacy of $\mathrm{Cu}$ biocides. J Agric Food Chem 62:6043-6052

Zeng Q, Zhang Y, Ji W, Ye W, Jiang Y, Song J (2014) Inhibitation of cellular toxicity of gold nanoparticles by surface encapsulation of silica shell for hepatocarcinoma cell application. ACS Appl Mater Interfaces 6:19327-19335

Zhang C, Uchikoshi T, Kitabatake T, Sakka Y, Hirosaki N (2013) Surface modification of $\mathrm{Ca}-\alpha-\mathrm{SiAlON}: \mathrm{Eu}^{2+}$ phosphor particles by $\mathrm{SiO}_{2}$ coating and fabrication of its deposit by electrophoretic deposition (EPD) process. Appl Surf Sci 280:229-234 